\section{A rodovia Pan-Americana e o Tampão de Darién: integração continental e áreas protegidas em zona de fronteira}

(4) Camilo Pereira Carneiro

Mestrado em Fronteiras e Direitos Humanos, Universidade Federal da Grande Dourados, Brasil ORCID: http://orcid.org/oooo-ooo1-7229-1298

César Augusto Reolon

Curso de Relações Internacionais, Escola Superior de Propaganda e Marketing, Brasil

\section{João Pedro Portela}

Curso de Relações Internacionais, Escola Superior de Propaganda e Marketing, Brasil

Recibido: 30 de mayo de 2018. Aceptado: 23 de julio de 2019.

\section{Resumo}

A existência de áreas protegidas nas fronteiras é uma solução recorrente no sistema internacional para solucionar conflitos entre Estados vizinhos. Muitas vezes, os limites internacionais sofrem intervenções políticas, o que resulta em danos à fauna e flora endêmicas. Na América do Sul, o Tampão de Darién é um dos muito exemplos de estratégia geopolítica criada como solução de disputas em zonas de fronteira. Com a independência do Panamá, em 1903, a fronteira entre esse país e a Colômbia se converteu em uma zona-tampão de bosques que bloqueia o trajeto da rodovia Pan-Americana. A falta de conexão entre os dois países perdurou durante todo o século XX e ainda hoje uma solução não é vislumbrada, ainda que a partir do século XXI, projetos de integração sul-americana tenham recebido um grande impulso com iniciativas como a IIRSA-COSIPLAN. Essa iniciativa foi responsável por interações mais intensas entre os países da América do Sul. Nesse sentido, o presente artigo apresenta uma análise do processo recente de integração da América do Sul em uma área de fronteira estratégica (o Tampão de Darién) e enfoca uma rodovia vital para os interesses econômicos e sociais do continente (a rodovia Pan-Americana).
Palavras-chave

Zona de fronteira Área protegidas Tampão de Darién

Pan-Americana IIRSA-COSIPLAN

\section{Palabras claves}

Zona de frontera Áreas protegidas Tapón de Darién Carretera Panamericana IIRSS-COSIPLAN 


\section{The Pan American Highway and the Darién Gap: continental integration and protected areas in a border zones}

\begin{abstract}
Protected areas in border zones it is a recurring way to solve conflicts between neighbouring States in the international system. Oftentimes, the international boundaries suffer politics interventions that impact the local fauna and flora. In South America, the Darién Gap is one among many geopolitics strategy examples created to solve border conflicts. From the independence of Panama in 1903, the border between Panama and Colombia became a buffer zone covered by a forest, which interrupt the Pan-American Highway. The lack of connection between the two countries persisted throughout the 20th century and even today a solution is not glimpsed. Even though from the 21 st century onwards, South American integration projects have received a great boost with initiatives such as IIRSA-COSIPLAN. This initiative was responsible for intense interactions between South America's countries. In this sense, the following article presents an analysis of the recent process of integration between South America countries in an area of strategic border (the Darién Gap) and focuses on a vital highway for the economics and socials interests of the continent (Pan-American Highway).
\end{abstract}

\section{Introdução}

A região que abrange o leste do Panamá e o noroeste da Colômbia é historicamente conhecida como Darién. No entanto, o termo sofreu alterações ao longo do tempo. $\mathrm{Na}$ realidade, Darién seria uma corruptela da palavra "Tanela", denominação atribuída no início da exploração colonial espanhola (Sauer, 1996 apud Runk, 2015). No que tange aos aspectos geográficos, na era colonial Darién correspondia à maior parte do istmo e mais tarde passou a denotar a região a leste da Cidade do Panamá até o noroeste da atual Colômbia. Em 1922, o governo panamenho criou a Província Darién e Darién foi redefinida domesticamente como uma província fronteiriça (Runk, 2015).

A região de Darién, que constitui a fronteira entre Colômbia e Panamá, estabelecida a partir de 1903, caracteriza-se desde sua origem por representar uma barreira entre os dois países, tendo em vista a ausência de conexão viária e a existência de áreas protegidas. Nesse sentido, Abínzano (2014) atenta para um fato, muito em voga nos países latino-americanos, que é a filosofia das fronteiras defensivas sob o marco da segurança nacional.

Por sua vez, Steiman (2011) afirma que áreas protegidas comumente são estabelecidas com a função de zona-tampão, enfatizando a ideia de fronteira política como obstáculo. Estados podem usar áreas protegidas transfronteiriças como zonas-tampão para impedir o acesso de grupos locais ou países vizinhos a áreas na zona de fronteira.

No que tange à conservação da natureza em áreas de fronteira cabe destacar que o tema ganhou relevância a partir da década de 1970, primeiramente concernente a uma preocupação hídrica entre os Estados nacionais, mas posteriormente estendendo-se para a proteção dos relevos fronteiriços. Até então, estas não eram pautas discutidas entre Estados vizinhos que compartilhavam um ecossistema em suas fronteiras.

Nas últimas décadas do século XX a diplomacia passou a se fazer presente em questões sobre o manejo de ecossistemas que se espraiam para mais de um país, se valendo de estratégias geopolíticas como a implantação de zonas-tampão, uma vez que existe a preocupação de defender o interesse e a soberania nacionais. Benedetti (2011) destaca

\section{Keywords}

Border area Protected areas Darién Gap Pan-American Highway IIRSA-COSIPLAN 
que a autoridade do Estado nacional sobre uma área determinada é questionável em um cenário de imperialismo, integração regional e globalização. Dessa forma, uma zonatampão também é passível de ser administrada de forma bilateral ou até multilateral (Beehner e Beinauer, 2016).

O Tampão de Darién constitui um exemplo da referida situação, em que diferentes interesses são manifestados: ambiental, econômico, social e geopolítico (presença dos parques nacionais somada aos interesses dos Estados - Colômbia e Panamá - e das populações originárias e entidades governamentais e não governamentais). A zona de fronteira correspondente ao Tampão de Darién é impactada pela presença de diferentes atores do Sistema Internacional. Nesse sentido, Haesbaert (2009a), recorda que o Estado não é mais o único ator capaz de intervir e causar mudanças, empresas transnacionais e grupos sociais também têm condições de fazer mudanças regionais e globais, podendo, inclusive, guiar certas ações do Estado.

Correspondendo a uma região de $160 \mathrm{~km}$ de largura, que abriga dois grandes parques nacionais declarados pela UNESCO como patrimônios da humanidade, o Tampão de Darién está inserido em um contexto marcado por tensões entre diferentes atores que se cruzam com elementos de políticas supranacionais. Estas tensões são referentes à finalização da rodovia Pan-Americana, aos debates acerca da construção de um canal alternativo pelo rio Atrato, à presença da agroindústria bananeira e dos cultivos de palma africana (coqueiro de dendê), além da pecuária bovina extensiva, da extração de madeira e da mineração de ouro e outros metais.

No que tange à conexão viária da zona de fronteira colombo-panamenha, o Tampão de Darién provoca uma interrupção no trajeto da rodovia Pan-Americana, autopista que conecta as três Américas (do Norte, Central e do Sul). Trata-se de um trecho de 108 quilômetros - 50 em território colombiano e 58 em território panamenho. A conclusão da rodovia foi interrompida há mais de 30 anos. Atualmente, os esforços para a retomada das obras partem do interesse unilateral do governo colombiano. Por sua vez, o Panamá não tem demonstrado interesse na conclusão da rodovia e vem buscando iniciativas de desenvolver a área a partir de investimentos em infraestrutura.

Uma vez contextualizado o tema, surgem duas indagações: Por que houve um posicionamento do Panamá no sentido de evitar uma possível integração fronteiriça num período de pujante debate acerca da integração regional na América Latina? A preocupação com a conservação da natureza seria realmente o fator-chave que impede a conclusão da rodovia Pan-Americana, ou essa seria uma justificativa estratégica usada para encobrir as reais intenções do governo panamenho sobre a zona de fronteira com a Colômbia? Nesse sentido, o presente trabalho tem o objetivo de analisar quais seriam os principais atores e seus interesses por trás da interrupção da rodovia Pan-Americana na região do Tampão de Darién.

$\mathrm{O}$ artigo foi dividido em quatro partes. Inicialmente será trabalhado o conceito de área protegidas, relacionando-o com situações de fronteira. Em seguida, serão apresentados os projetos que tangem à integração fronteiriça na América do Sul, abordando especificamente a IIRSA-COSIPLAN (Iniciativa para a Integração da Infraestrutura Regional Sul-Americana-Conselho Sul-Americano de Infraestrutura e Planejamento). A terceira parte do trabalho abarcará a história da rodovia Pan-Americana e suas marcas na zona de fronteira colombo-panamenha. Por fim, o artigo trará uma análise do Tampão de Darién com enfoque na história da região e nos principais atores que impactam/limitam o seu desenvolvimento. Trata-se de uma pesquisa básica, qualitativa, sob a ótica da Geografia Política e das Relações Internacionais, pautado em análise bibliográfica e documental, enriquecida por cartografia produzida pelos autores. 


\section{Áreas protegidas em zonas de fronteira}

A convivência com o meio ambiente é intrínseca ao ser humano, uma vez que ele sempre dependeu da natureza para sua existência. Apesar do desenvolvimento da sociedade ocidental e de sua passagem de dependência do meio ambiente para uma forma de ameaça ambiental e, consequentemente, evolução urbana ocasionada pelo crescimento populacional, ainda existem outras sociedades, não menos complexas, com vínculo com a natureza (Chaves, 2016).

Com o progresso do mercantilismo, no final do século XV, houve o contato da sociedade europeia com os povos de outros continentes, que passaram a ser colonizados e que ainda viviam em territórios muito pouco urbanizados em relação à Europa. Com o imperialismo ocorreu uma grande devastação dos territórios colonizados, impactando a fauna e a flora por meio de desmatamento, exploração de recursos e da urbanização.

Os impactos causados pela revolução industrial e as consequências causadas ao meio ambiente fizeram surgir na Europa uma corrente intelectual preocupada em pensar soluções para reverter os impactos causados na natureza. No final do século XIX, a preocupação ambiental ganhou força e a natureza começou a ser vista de outra maneira. Essa preocupação chegou a repercutir fora da Europa e, em 1872, foi estabelecido o primeiro parque nacional do mundo, Yellowstone, nos Estados Unidos (Menezes, 2015).

Não obstante, apenas na metade do século XX é que a ideia de preservar a biodiversidade dos parques nacionais passou a ganhar força, em meio a um debate iniciado pela União Internacional de Conservação da Natureza (UICN) (Menezes, 2015). O objetivo das áreas protegidas - parques nacionais, reservas ambientais, territórios indígenas ou paisagens com características semelhantes - é a conservação do ecossistema, ambiente com inter-relação entre seres vivos e a natureza de determinada região. De acordo com a União Internacional para a Conservação da Natureza e dos Recursos Hídricos (UICN), áreas protegidas configuram uma superfície de terra ou mar especialmente consagrada à proteção e à manutenção da diversidade biológica, assim como dos recursos naturais e culturais associados, sendo manejada através de meios jurídicos ou outros meios eficazes (Ferrero, 2018).

As áreas protegidas conservam ambientes e espécies como também têm impactos sobre o território e as populações humanas que vivem dentro e no entorno de tais espaços (Ferrero, 2018). O ecossistema das áreas protegidas, por vezes, estende-se para além das fronteiras dos Estados nacionais, fazendo com que a segurança daquela zona seja de competência de ambos os Estados. Os cuidados com a biodiversidade existente, contudo, contrariam o princípio de soberania nacional, pois as decisões a respeito de uma área protegida fronteiriça devem ser consentidas por todas as partes, o que pressupõe que os governos devam agir em cooperação para fiscalizar o território e alcançar um objetivo comum (Menezes, 2015).

Ao redor do globo, existem diversas áreas que possuem seus ecossistemas atravessados por fronteiras internacionais, o que faz com que seja necessária uma cooperação entre países vizinhos no que tange ao manejo das áreas protegidas transfronteiriças, como no caso de Waterton-Glacier (fronteira Canadá-Estados Unidos), El Petén (fronteira GuatemalaMéxico-Belize), Cordilheira do Condor (fronteira Peru-Equador), entre outros.

Steiman (2011) recorda que áreas protegidas em zonas de fronteira são defendidas como capazes de conservar ecossistemas que ultrapassam limites políticos entre Estados nacionais, configurando um ponto de partida para uma maior cooperação 
regional. Não obstante, a autora lembra que áreas protegidas são comumente estabelecidas dentro de uma concepção de zona-tampão, objetivando a estabilização da linha de fronteira.

No caso do Tampão de Darién, existe uma cooperação entre os governos panamenho e colombiano através de diversos memorandos para garantir a segurança e o desenvolvimento da fronteira. A preocupação ambiental dos dois países se faz notar, uma vez que a zona fronteiriça é caracterizada por uma grande floresta equatorial que possui uma biodiversidade única e diversas áreas de proteção ambiental, além de parques nacionais.

A preocupação com o meio ambiente foi uma das justificativas usadas pelo governo panamenho (influenciado pelos Estados Unidos na década de 1970) para impedir a construção do trecho da Rodovia Pan-Americana em sua fronteira com a Colômbia. A medida inviabilizou a conexão das Américas, uma vez que a rodovia é interrompida no Tampão de Darién. As obras estão estagnadas há mais de vinte anos, tanto no lado panamenho quanto no colombiano.

O Tampão de Darién abriga populações indígenas e de descendentes de escravos africanos nos parques nacionais tanto do lado panamenho quanto no território colombiano. Essas populações transitam livremente entre os dois lados da fronteira, que também é atravessada por diversos imigrantes ilegais e grupos paramilitares (Miraglia, 2016). No Panamá existe uma legislação que confere aos indígenas níveis de autonomia e formas de governo próprias, havendo inclusive áreas protegidas administradas de maneira autônoma. Já na Colômbia, o Art. 7 do Decreto 622, de 1977, estabelece que não existe incompatibilidade entre parque nacional e resguardo indígena declarado (FAO, 2008).

Apesar das legislações destacadas, a realidade da zona fronteiriça entre Panamá e Colômbia é marcada pelo abandono por parte dos governos nacionais, que por questões geopolíticas, privilegiaram o desenvolvimento das regiões mais centrais de seus respectivos territórios, economizando esforços e incentivos em uma região caracterizada por desafios de desenvolvimento.

\section{Projetos de integração fronteiriça nas Américas}

De acordo com Teixeira e Anselmo (2017), os projetos embasados na cooperação entre os Estados nacionais, via de regra, não apresentam sucesso na América Latina, pois a herança colonial ainda impacta os acordos estratégicos que os países latinoamericanos tentam implementar, visto que existem interesses de atores externos que interferem na região. O processo de integração latino-americano é recente, remonta ao final da Segunda Guerra Mundial, quando da criação da CEPAL (1948), e perpassa a implementação de diversas iniciativas (nem todas bem-sucedidas) como ALALC (1960), CAN (1969), TCA (1978), ALADI (1980), MERCOSUL (1991), IIRSA (2000), UNASUL (2008) e COSIPLAN (2009).

Uma das principais iniciativas para o desenvolvimento da infraestrutura na América do Sul, a IIRSA foi criada sob uma lógica neoliberal, com foco na integração e desenvolvimento de infraestruturas de telecomunicações, energia e transporte, com a finalidade de promover o fluxo de commodities através do subcontinente sul-americano (Pereira Carneiro, 2016). Assim, grande parte das conexões entre os Estados nacionais fica sob responsabilidade e fiscalização de um projeto de integração criado pelos próprios atores sul-americanos, mas cujo objetivo é contemplar a função de área produtora e exportadora de commodities. 


\section{Integração Continental: a rodovia Pan-Americana}

Considerada a rota mais extensa do mundo, a Pan-Americana possui 48 mil quilômetros de extensão e atravessa de norte a sul todo o continente americano, desde o Alasca até a Argentina (McCarthy, 2014). O plano da rodovia foi definido na década de 1920. Em 1925 ocorreu, em Buenos Aires, a primeira reunião do Congresso Pan-Americano, onde foi proposto o estabelecimento de um Congresso Pan-Americano de Rodovias estável (Cuello, Campis e Guerrero, 2012).

A rodovia Pan-Americana foi concebida originalmente para fomentar as relações comerciais entre os Estados Unidos e os países da América Latina. As pesquisas para a construção da rodovia tiveram início em 1929. O primeiro trecho foi inaugurado em 1934, entre o Texas e o México. Em 1955 a Colômbia, os Estados Unidos e o Panamá criaram o Subcomitê de Darién da Rodovia Pan-Americana. Foi o engenheiro panamenho Tomás Guardia que cunhou o termo Tampão de Darién (Darien Gap, em inglês) para dar ideia gráfica do que Darién representava na batalha por estabelecer a conexão viária das Américas (Runk, 2015).

A Pan-Americana pode ser considerada um símbolo de integração das Américas, em sua extensão atravessa diferentes biomas e regiões com grande diversidade cultural. A rota tem início em Prudhoe Bay, no Alasca, região banhada pelo Oceano Ártico, com temperaturas que podem atingir $-43^{\circ} \mathrm{C}$. A rodovia segue dentro do território canadense, atravessando Edmonton, capital do distrito de Alberta, e sua vizinha Calgary. Já no território dos Estados Unidos, a rodovia passa por importantes cidades como Denver e San Antonio (existe ainda uma rota alternativa que também faz parte da rodovia Pan-Americana, seguindo por Minneapolis e Dallas). Após cruzar o território mexicano de norte a sul, a rodovia segue um trajeto que passa por todos os países da América Central ístmica até ser interrompida no Tampão de Darién, no Panamá. Embora seja interrompida na fronteira panamenho-colombiana, a PanAmericana é considerada uma rodovia que percorre o continente americano. A partir do território colombiano a rodovia Pan-Americana prossegue através dos territórios de Equador, Peru, Chile e Argentina (Figura 1).

Ao longo do seu trajeto, a rodovia atravessa áreas de grande diversidade e que possuem vestígios da América de colonização ibérica e anglo-saxônica como também ruínas do período pré-colombiano (herança de civilizações como a maia, a asteca e a inca, entre outras). A rodovia atravessa a ponte das Américas, sobre o Canal do Panamá, um ponto considerado o divisor entre América do Norte e América do Sul na regionalização em vigor em países como os Estados Unidos (algo que não se aplica no Brasil, por exemplo, onde as Américas possuem uma regionalização em três subcontinentes, a saber: América do Norte, América Central e América do Sul). 


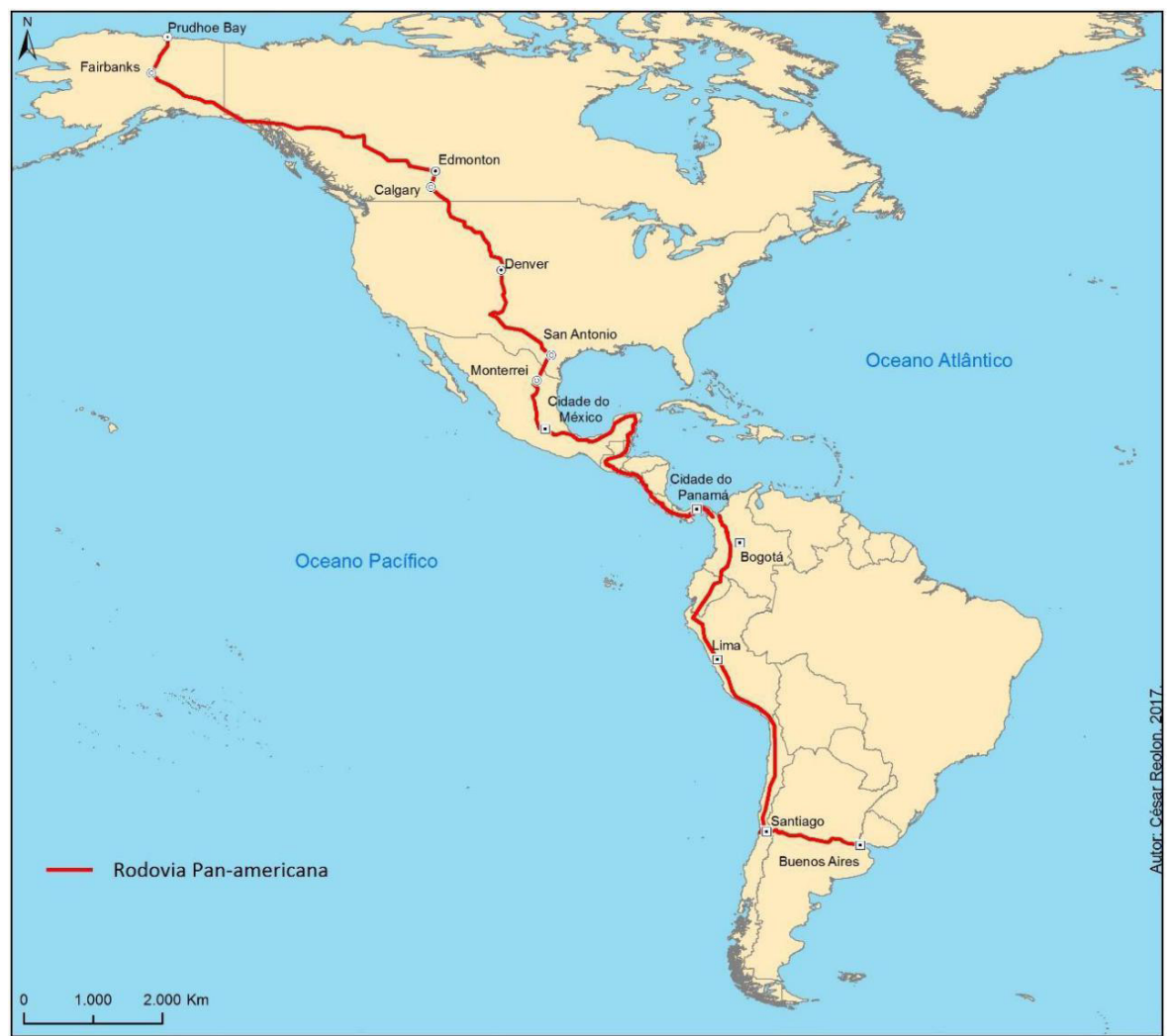

Figura 1. Rodovia Pan-Americana. Autor: César Reolon, 2017.

A inexistência de um único trajeto determinado consensualmente entre os países americanos traz problemas para viajantes e turistas que desejam percorrer a rodovia PanAmericana. Em alguns trechos, a rodovia oferece mais de uma opção de caminho para os viajantes, havendo ainda constantes obras de manutenção e duplicação em diferentes países. As condições climáticas (os períodos de estiagem e chuva) interferem no grau de dificuldade em cruzar a rodovia. Destaca-se o grande obstáculo representado pela Cordilheira dos Andes em alguns pontos específicos existentes em países como Chile e Peru.

Apesar de ser uma rodovia importante para a conexão continental e mesmo hemisférica, a Pan-Americana carece de ligações com o interior da América do Sul. Cabe destacar que recentemente algumas obras viárias começaram a ser implementadas no subcontinente, mas isso vem ocorrendo de maneira um tanto quanto descoordenada e pontual, sobretudo através de projetos da IIRSA-COSIPLAN. Nesse sentido, merece destaque a obra da Estrada do Pacífico, que liga o norte do Brasil ao litoral peruano, cujo asfaltamento só foi concluído em 2010. Scheibe (2013) afirma que a ausência de rodovias conectando os países sul-americanos explica-se pela história de colonização deste território, cujas atividades econômicas principais sempre estiveram associadas ao mercado externo. Ainda hoje, os principais produtos de exportação sul-americanos são commodities (minérios, petróleo, soja e outros gêneros agrícolas).

\section{Tampão de Darién}

O trecho onde a conexão viária entre as Américas é interrompida é caracterizado pela presença de uma área florestal com grande diversidade de fauna e flora. Isso decorre da formação do istmo, há 3 milhões de anos atrás, que gerou uma ponte de terra entre 
a América do Norte e a América do Sul e resultou no intercâmbio de espécies entre as porções meridional e setentrional das Américas, fazendo com que a região de Darién passasse a ter uma rica biodiversidade, configurando um hotspot nos mapas de áreas protegidas do planeta (Runk, 2015).

Além de abrigar diversos grupos indígenas, inclusive parques e diferentes áreas de proteção ambiental (caso do Parque Nacional de Darién, que está presente por toda a fronteira, com extensão de 579.000 hectares, chegando a confundir-se com o parque Los Katios, ambos declarados patrimônios da humanidade pela UNESCO). A região que abriga o Tampão de Darién - também conhecida como Amazônia panamenha (Méndez, 1988) - resulta de uma estratégia geopolítica, uma vez que serve como zona-tampão entre Colômbia e Panamá, antigo território colombiano que se tornou independente no início do século XX.

A referida zona-tampão também configura uma barreira natural que impede a passagem de doenças infectocontagiosas, motivo que, somado aos presumidos impactos ambientais, como se verá mais adiante, serviu como justificativa para o impedimento da construção da rodovia (Suman, 2007). A figura 2 monstra a dimensão da área florestal contemplada pelo Tampão de Darién. Também atesta o isolamento da zona de fronteira, que é distante das regiões centrais dos dois países e sofre com a precariedade da infraestrutura e insuficiência de recursos para as populações locais (Nicolas, 2007).

A conclusão da rodovia Pan-Americana poderia resultar em um possível desenvolvimento local, contudo, muitos autores trazem à luz o paradoxo do megaprojeto, a ideia de que quanto mais caro um projeto, mais impactos negativos relacionados à população local, à economia do Estado - causado pelo empréstimo para a realização da construção - aconteceriam, devido à exploração que será feita dos recursos ou da própria área (Silva, 2015).

A ideia de se construir uma via que conecte todo o continente americano existe desde 1880. O projeto quase se materializou, haja vista que na metade da década de 1960, a construção foi interrompida na altura do Tampão de Darién. Na época, havia dois motivos que barraram a continuação. Primeiro os casos de febre aftosa que aconteciam somente na América do Sul e, caso não houvesse o tampão, poderiam atingir a América Central e a América do Norte. O segundo motivo foi uma ação judicial impetrada no tribunal de Washington por ambientalistas que alegavam que impactos ambientais e sociais seriam causados (Suman, 2007). Houve pouco progresso no trajeto da PanAmericana depois desses acontecimentos e, desde 1983, não acontecem avanços da rodovia.

Cabe ressaltar que, embora do lado colombiano tenham sido realizados estudos técnicos e ambientais muito confiáveis no sentido de superar os obstáculos para a conclusão do trecho final da Pan-Americana, do lado panamenho persiste a oposição ao projeto, prevalecendo os pretextos e interesses do setor pecuarista, cujos membros, de grande poder político, passaram a disseminar preconceitos anticolombianos que obscurecem a integração econômica e comercial Panamá-Colômbia e a importância da rodovia no contexto do desenvolvimento e integração da América Latina. 


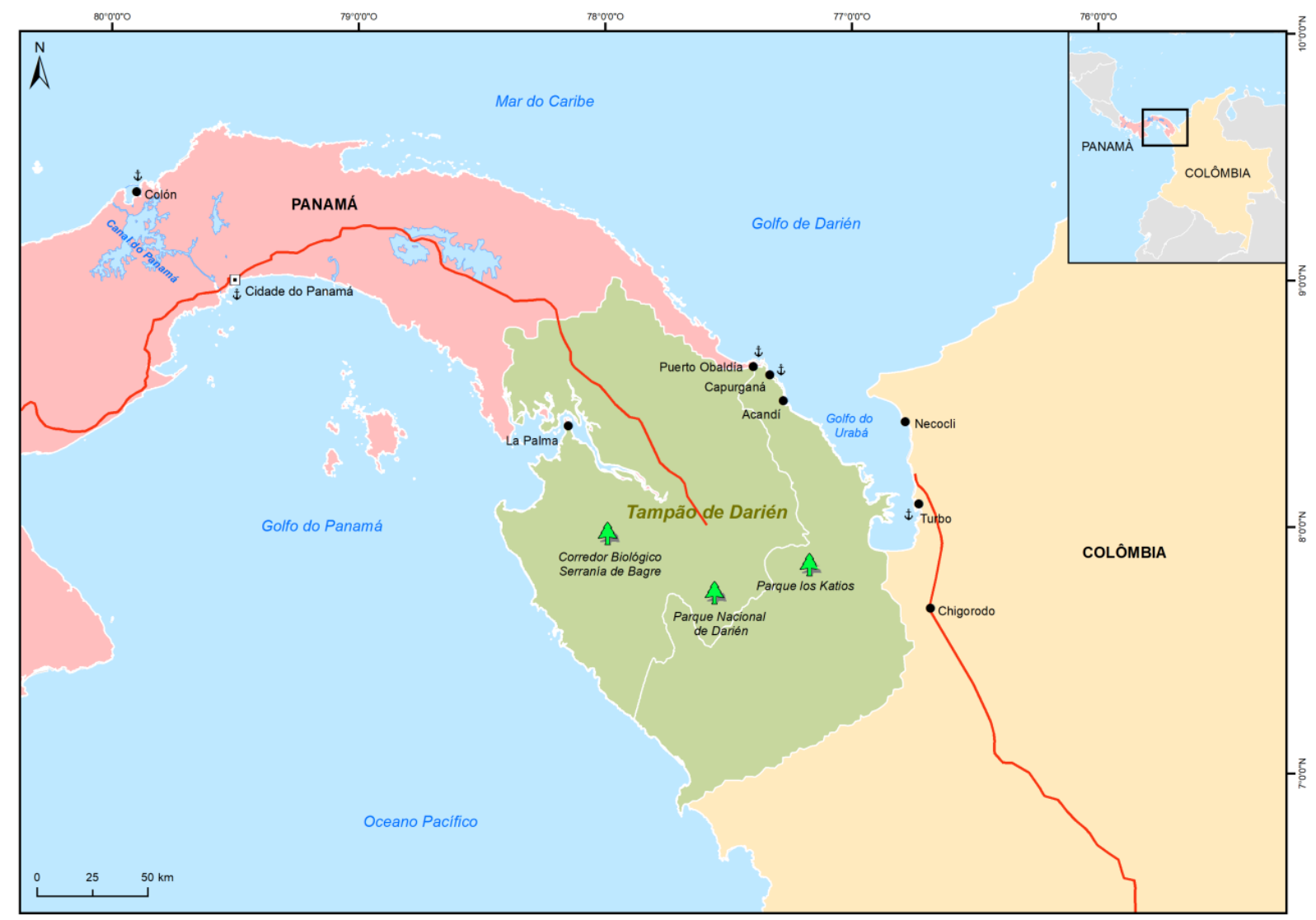

Figura 2: Tampão de Darién. Autor: Camilo Pereira Carneiro. 2019.

Por detrás da oposição panamenha, que evoca os futuros danos ecológicos e a propagação da febre aftosa (erradicada no Darién colombiano há mais de duas décadas) se escondem interesses dos pecuaristas panamenhos que, por um lado, visam a derrubada de extensas áreas florestais e a exploração da madeira e, do outro, enxergam com preocupação a futura competição que a abertura da rodovia trará ao mercado de carne (Mosquera, 2007).

Nesse contexto, a criação do Parque Natural de los Katios foi parte da estratégia dos pecuaristas panamenhos que alegavam que a iniciativa obedecia os interesses dos Estados Unidos de criar uma reserva forestal para a conservação da biodiversidade em Darién, quando as verdadeiras razões foram essencialmente econômicas, e além dos interesses dos pecuaristas, estavam aqueles da indústria de carnes e lácteos estadunidenses. No caso do Panamá, as principais organizações ambientalistas são lideradas por membros das famílias de proprietários de extensas áreas de criação de gado (Mosquera, 2007).

A partir da década de 1990, volumosos investimentos em desenvolvimento e conservação em Darién coincidiram com a saída dos Estados Unidos da Zona do Canal, em 1999. Em 2003, a USAID contribuiu com 6,5 milhões de dólares para o Parque Nacional de Darién. Os Estados Unidos também investiram no Panamá como forma de minorar os impactos (efeito spillover) causados no país pela Guerra às Drogas na vizinha Colômbia (Runk, 2015).

Ainda que não haja uma conexão terrestre, existem outras formas de cruzar a fronteira entre os países. Frequentemente, muitos imigrantes ilegais, coiotes - traficantes de pessoas -, grupos paramilitares fazem uso de rotas na floresta (Miraglia, 2016). 
Mesmo sem haver uma conexão rodoviária formal, não se percebe uma situação de contenção que, conforme Haesbaert (2009b) é uma forma paliativa de o Estado criar um efeito-barreira. Muitos viajantes utilizam barcos que ficam localizados em cidades costeiras para fazer a travessia entre Colômbia e Panamá. O método costumeiro para cruzar a fronteira é por meio de lanchas que partem da cidade de Turbo (Colômbia) e se dirigem até a cidade de Capurganá (Colômbia), na fronteira, de onde rumam até Porto Obaldía (Panamá) (Oim, 2007).

Os viajantes que desembarcam na costa panamenha e passam pelo posto de migração, podem utilizar um navio cargueiro, lancha ou avião para ir até a Cidade do Panamá. O difícil processo de cruzar a fronteira entre os países se deve à falta de investimento em infraestrutura na região, bem como à preocupação com a conservação da natureza e à presença, no lado colombiano, de grupos armados que transitam livremente pelo Tampão de Darién (Viveros, 2009). A zona de fronteira vem sendo palco de disputas por ser área de interesse dos Estados nacionais e de grupos paramilitares, mas também de povos originários e multinacionais que buscam se estabelecer ali (Suman, 2007).

\section{Relações entre Panamá e Colômbia}

O Panamá foi parte integral de todas as formas de organização política e territorial que a República da Colômbia teve desde 1831 até 1903 (Galindo, Cortes, 2017). Em 1903, movimentos regionalistas locais do Departamento do Panamá, com o apoio dos Estados Unidos, conseguiram a separação da Colômbia e conquistaram a independência (a Colômbia só reconheceria o país em 1914). Entre as razões para que o Departamento do Panamá declarasse sua independência cabe mencionar o fracasso da construção do Canal do Panamá pela Compagnie Universelle du Canal du Panamá; a Guerra dos Mil Dias (1899-1902), que ocasionou grandes perdas humanas e materiais no istmo; as antigas pretensões autonomistas da classe política panamenha e o rechaço do Tratado Herrán-Hay (assinado em 1903) por parte do Congresso da Colômbia. Os separatistas panamenhos foram respaldados pelo governo do presidente estadunidense Theodore Roosevelt, para o qual a construção do Canal do Panamá era um objetivo estratégico (Galindo e Cortes, 2017).

Em 1924 foi assinado o Tratado Velez-Victoria, que estabeleceu os limites entre Panamá e Colômbia (Montenegro, 1988). Não obstante, as políticas promovidas pelos dois Estados nacionais para a região fronteiriça se iniciaram a partir de 1992, com um memorando que planejou ações para desenvolvimento local. A iniciativa, contudo, teve pouca eficácia.

Gonzáles e Ruiz (2018) recordam que na década de 1990 o Panamá suprimiu seu exército em função do passado de ditaduras e golpes militares. Dessa forma, a fronteira com a Colômbia é caracterizada pela ausência de um exército panamenho. Nesse cenário, a fronteira terrestre, coberta de florestas e repleta de adversidades topográficas configura uma "barreira natural".

Cabe destacar que Panamá e Colômbia configuram-se países de trânsito para imigrantes, tanto legais quanto ilegais que têm como destino final os Estados Unidos. Com o recente estreitamento e o aumento do rigor das políticas migratórias muitos imigrantes vêm sendo impedidos de chegar aos Estados Unidos, sendo contidos nos territórios do Panamá e da Colômbia, realidade que explica o aumento do número de imigrantes ilegais - a maioria cubanos, mas também haitianos e africanos - nos dois países (Miraglia, 2016). 
As políticas de combate à imigração ilegal, tanto do Panamá quanto da Colômbia, têm um caráter mais humanitário, ainda que esses países tenham aumentado o controle sobre suas fronteiras após o início do governo Trump, iniciado em 2017. O tratamento mais humanitário dos dois Estados deve-se à preocupação das autoridades de Bogotá e Cidade do Panamá com o tráfico de pessoas e a presença de grupos paramilitares (Luna, 2016).

Runk (2015) afirma que a partir dos primeiros anos do século XXI uma nova narrativa passou a associar Darién às ameaças das guerrilhas, do tráfico de drogas e dos sequestros, bem como a elevados níveis de violência. Narrativa esta amplamente difundida na imprensa internacional. Uma tendência ao exagero muito pronunciada quando comparada à imprensa doméstica.

No que tange à rodovia Pan-Americana, pautas para desenvolvimento e continuação do trecho que está por terminar vêm sendo levantadas pelo governo colombiano. Não obstante, o governo panamenho tem demonstrado que não vislumbra vantagens econômicas na conclusão da obra e tem obstaculizado o diálogo para a construção da rodovia temeroso com os possíveis impactos relacionados à segurança, economia e política (Suman, 2007). Nesse sentido, o governo panamenho tem feito da preocupação com a conservação da natureza uma estratégia para evitar a finalização da rodovia. Uma justificativa que não se sustentaria de acordo com Nicolas (2007), que entende que os motivos para o impedimento da construção da rodovia acabaram, uma vez que já existem rotas alternativas que causariam danos menores.

\section{Os projetos de conexão física e os impactos locais}

Em relação ao futuro da conexão física entre Colômbia e Panamá, Steiman (2011) afirma que integrações entre Estado, comunidades locais e setor privado não são ponto pacífico. A autora traz o exemplo de áreas protegidas transfronteiriças no continente africano. Algumas das quais são implantadas por grandes empreendimentos ecoturísticos sob promessa de repartição de benefícios com comunidades locais preexistentes. No entanto, tais empreendimentos demoram a se consolidar e não costumam gerar acumulação local de capital.

Suman (2007), por sua vez, destaca um estudo de uma consultoria de ecologia e meio ambiente, nos anos 2000, que apontou que o custo médio para término da rodovia Pan-Americana estaria estimado entre 250 e 450 milhões de dólares, dependendo da rota a ser escolhida. Além dos impactos econômicos, existem ainda questões políticas e sociais que dificultam a conclusão da rodovia. Os habitantes das áreas protegidas seriam afetados pela obra, pois teriam seus territórios descaracterizados e, com o fim do isolamento, a área poderia ser tomada pelo agronegócio (ampliação de lavouras sobre a mata nativa). Atualmente, além da Chiquita Brands (atual denominação da United Fruit), conglomerado multinacional e grande produtor de banana, melão, abacaxi e outras frutas tropicais, empresas estrangeiras, envolvidas na exploração da madeira, presentes na Colômbia e no Panamá, causam impactos na região de Darién.

Outro cultivo que causa pressão sobre as áreas selváticas de Darién é o da palma africana. Companhias palmicultoras - a Urapalma em particular - se consolidaram na região de Darién nas últimas décadas em terras de populações deslocadas pela violência (em função do conflito armado colombiano). As companhias, associadas a grupos paramilitares, introduziram em Darién e em regiões vizinhas pessoas deslocadas de outras áreas da Colômbia com o objetivo de criar uma base laboral submissa, alheia à invasão de áreas de titulação coletiva de afrodescendentes e indígenas (Sánchez Acosta, 2009). 
A presença de forças paramilitares em território colombiano é um fator que preocupa o governo panamenho (Ali, 2012). Há o temor por parte das autoridades panamenhas de que a rodovia sirva como um fator facilitador para aliviar a presença de grupos paramilitares na Colômbia, que já conseguem transitar em território panamenho mesmo sem a rodovia. Esse é um fator muito relevante para o governo panamenho, uma vez que as forças armadas do país foram extintas em 1989 e, hoje, as forças de defesa do Panamá não têm força para conter com eficiência grupos guerrilheiros. O mesmo vale para o tráfico de drogas, de pessoas e de armas que acontece entre as fronteiras.

Cabe ressaltar ainda que, além do megaprojeto da rodovia Pan-Americana, existe um projeto de conexão interoceânica que pode gerar grandes impactos na região do Tampão de Darién. Trata-se do projeto da ferrovia entre as cidades colombianas de Turbo, situada no Golfo de Urabá, no litoral caribenho, e Cupica, no Pacífico, que contempla ainda a construção de uma hidrovia, a Hidrovía del Atrato. O projeto Urabá-Cupica configura alternativa de interesse para os chineses, baseada em dois portos profundos, conectados por uma ferrovia interoceânica de $220 \mathrm{~km}$, que mobilizaria 40 milhões de toneladas por ano. O projeto tem um custo estimado em US \$ 7,6 bilhões (Duque, 2014).

O referido projeto não consta na carteira de Projetos da IIRSA-COSIPLAN, que, por sua vez, em seu eixo Andino, que abarca a Colômbia e países andinos vizinhos (e não abrange o Panamá), possui um projeto de corredor bioceânico denominado Conexión Pacífico-Bogotá-Meta-Orinoco-Atlántico. Tal projeto faz parte do Grupo 4 do eixo Andino e, ainda que seu trajeto previsto não vá atravessar áreas do Tampão de Darién, impactará esta região. Uma vez concluído, fará com que o Tampão de Darién passe a ficar entre dois corredores bioceânicos - o projeto da IIRSA-COSIPLAN e o Canal do Panamá -, vindo a sofrer os impactos resultantes dos fluxos de embarcações e do transporte de cargas, entre outros (COSIPLAN, 2017). Cenário que não é vislumbrado nos estudos e projetos implementados no âmbito da IIRSA-COSIPLAN. Além de não contemplar a fronteira entre Colômbia e Panamá de maneira direta, a IIRSA-COSIPLAN não contempla uma integração da América do Sul com a América Central, o que consequentemente iria potencializar o aumento dos fluxos de pessoas, mercadorias e serviços também com os países da América do Norte.

Ainda no âmbito dos projetos de interconexão regional, merece destaque o Plan Puebla Panamá (PPP), iniciado em 2001, que tem como objetivo integrar os países da América Central e o México, voltado ao desenvolvimento de infraestrutura (principalmente energia) e à exploração e comercialização de recursos naturais (Luhrs; Zepeda, 2002).

Pela magnitude e área de atuação do PPP, os impactos ambientais tendem a ser maiores do que aqueles decorrentes da finalização da rodovia Pan-Americana. Ainda assim, o PPP beneficiaria o território do Panamá, enquanto a conclusão da rodovia iria implicar em uma série de controles fronteiriços que o governo panamenho teria dificuldade em implantar (Suman, 2007), visto que a rodovia atravessaria parques nacionais, áreas de povos indígenas, podendo abrir espaço para grupos paramilitares existentes na região e facilitar a passagem de imigrantes ilegais (tráfico de pessoas), o narcotráfico e o estabelecimento de indústrias extrativas.

\section{Considerações finais}

O Tampão de Darién, uma extensa área de floresta que abriga grande diversidade de plantas e animais, além de ser o lar de tribos indígenas, tem se notabilizado pela pouca atenção recebida pelos Estados nacionais americanos. A região chega a estar ausente 
em iniciativas dirigidas à integração física continental como a IIRSA-COSIPLAN, principal ferramenta de integração dos países da América do Sul, que não possui projetos voltados para a zona de fronteira colombo-panamenha.

Os interesses divergentes envolvendo o Tampão de Darién, que colocam de lados opostos os governos do Panamá e da Colômbia, fazem com que estratégias políticas sejam utilizadas pata obstaculizar a conclusão da rodovia Pan-Americana. A finalização dos 108 quilômetros da rodovia Pan-Americana envolve três fatores: ambiental, social e diplomático.

Em relação ao fator ambiental, cabe destacar que a pavimentação do trecho implicaria em desflorestamento de muitos hectares de selva, afetando a fauna e a flora da região. No que tange a uma das justificativas mais usadas pelo Panamá, a preocupação com a conservação da natureza, Ferrero (2018) destaca que as áreas protegidas emergem das formas pelas quais os Estados constroem seus territórios, por tanto, não são apenas maneiras de governar os territórios como também de dar-lhes uma marca física. As áreas protegidas constituem formas de presença do Estado onde se põe em relevo certas formas de gerir recursos naturais, paisagens e populações humanas.

Quando em zonas fronteiriças, a conservação da natureza acaba por influenciar os processos de integração regional. Nesse sentido, algumas áreas protegidas podem acabar servindo como obstáculos à integração interestatal (caso do Tampão de Darién), enquanto outras podem servir como fator de cooperação entre países lindeiros, caso do Waterton-Glacier, entre Canadá e Estados Unidos. A problemática se encontra no tipo de uso atribuído a zonas de fronteira atravessadas por ecossistemas naturais e áreas protegidas. São os agentes estatais e os interesses das elites nacionais de cada lado da fronteira que determinarão, caso a caso, o papel da proteção do meio ambiente.

Por sua vez, o fator social está relacionado às comunidades de Darién cujas terras serão atravessadas pela rodovia, caso a mesma venha a ser concluída. Povos indígenas, como os emebrá, wounan e kunas ou tule, além de comunidades quilombolas, não são favoráveis à finalização da rodovia. Mesmo aqueles indivíduos conscientes de que a atual situação resulta em isolamento e traz consequências em temas como assistência à saúde, por exemplo. Para muitos desses povos a floresta é um território ancestral e destruí-la significa mudar seus modos de vida e costumes, além da ameaça à sua cultura representada pelo aumento do fluxo de pessoas que passarão a transitar pela região. Por outro lado, alguns agricultores e comerciantes da zona a ser pavimentada entendem que a conclusão da rodovia representaria um grande impulso para a economia e para suas comunidades, resultando em uma melhoria das condições de vida.

Quanto ao fator diplomático, há o risco de que a finalização da rodovia faça com que as problemáticas da Colômbia se transladem ao Panamá e, consequentemente, à América Central e aos Estados Unidos de maneira muito mais sensível. Portanto, não se trata de falta de recursos para a conclusão da obra, mas sim da vontade política dos governos, verdadeiro motivo que impede a sua finalização.

Por fim, Cuello, Campis e Guerrero (2012) entendem que é possível imaginar novas formas de organizar a vida social, econômica e cultural por meio de reorientação dos sistemas econômicos e tecnológicos. Isso implica que os desejos integracionistas de desenvolvimento de Darién devem superar sua concepção sobre o papel das comunidades indígenas como perpetuadoras do subdesenvolvimento da zona e de elas próprias. A integração regional deve ser assumida como um objetivo que gera o máximo de utilidades na medida em que for possível incorporar os interesses de ambientalistas, grupos indígenas, econômicos e políticos que percebem a rodovia Pan-Americana como via direta para a melhoria das condições socioeconômicas locais, sem excluir os interesses de cada uma das partes. 


\section{Q Bibliografia}

» Abínzano, R. (2014). Procesos transnacionales en las regiones de frontera: la Triple Frontera en el sistema mundo. Ideias, 5(2), 161-185.

»Ali, M. (2012). Megaproyectos y efectos perversos de la modernidad: el bizarro caso de Uraba. Perfiles Libertadores, 8(8) 72-80.

»Benedetti, A. (2011). Territorio: concepto integrador de la geografia Contemporánea. En: P. Souto (Ed.), Territorio, lugar, paisaje:. Praticas y conceptos básicos en geografía (11-82). Buenos Aires: EFFL/UBA.

» Beehner L., Beinauer, G. (2016). The Futility of Buffer Zones in International Politics. Orbis, 6o(2) 248-265.

»Chaves, L. (2016). História das Américas I. Sobral: Inta.

»Cosiplan (2017). Cartera de Proyectos 2017. Buenos Aires: Cosiplan/Foro Técnico IIRSA. Recuperado de https://www.flipsnack.com/IIRSA/informe-de-lacartera-de-proyectos-del-cosiplan-2017.html (14/08/2019).

»Cuello, C., Campis, E., Guerrero, I. (2012). Colombia, Panamá y la Ruta Panamericana: Encuentros y Desencuentros.Memorias. Revista Colombiana de Historia y Arqueología desde el Caribe Colombiano, 9(16), 101-130.

»Duque, G. (2014). Ferrocarril Interoceánico Verde para Colombia. Manizales: Universidad Nacional de Colombia.

»FAO. Organización de las Naciones Unidas para la Agricultura y la Alimentación (2008). Pueblos Indígenas y Áreas Protegidas en América Latina. Santiago de Chile: Oficina Regional de la FAO para América Latina y el Caribe.

»Ferrero, B. (2018). Tras una defnición de las áreas protegidas. Apuntes sobre la conservación de la naturaleza en Argentina. Revista Universitaria de Geografía, 27(1), 99-117.

» Galindo, A., Cortes, J. (2017). Geopolitica y perdida de territorio colombiano. Revista Geopolítica Fronteiriça, 1(1) 99-119.

»González, C., Ruiz, F. (2018). Una aproximación geopolítica a la política binacional de seguridad fronteriza entre Colombia y Panamá. Revista Ópera, 23, 81-9 6.

» Haesbaert, R. (2009a). Elementos para uma nova regionalização em um mundo global desterritorializado. En: M. Guibert (Ed.) Le bassin du Río de la Plata. Développement local et intégration régionale (27-49) Toulouse: Presses Universitaires du Mirail.

" Haesbaert, R. (2009b). Territórios e Territorialidades: Teorias, Processos e Conflitos. São Paulo: Expressão Popular.

»Luhrs, M., Zepeda, A. (2002). El Plan Puebla-Panamá y las políticas de desarrollo: Un análisis crítico. Espiral, 9(25), 69-105.

»Luna, K. (2016). The Continuing Growth of Cuban Migration. Washington D. C.: Center For Immigration Studies.

» Mccarthy, C. (2014). El silencioso Darién: El tapón invencible de la carretera Panamericana. BBC Mundo. Recuperado de http://www.bbc.com/mundo/ 
noticias/2014/o8/140814_darien_panamericana_tapon_dairen_finde_hr (14/08/2019).

" Méndez, H. (1988). Panamá. Madrid: Anaya.

»Menezes, P. (2015). Áreas de preservação ambiental em zona de fronteira: Sugestões para uma cooperação internacional no contexto da Amazônia. Brasília: Funag.

" Miraglia, P. (2016). The invisible migrants of the Darién Gap: evolving immigration routes in the Americas. Washington D. C.: Council on Hemispheric Affairs.

"Montenegro, J. (2007). Geografía Política: tensión en las fronteras de colombia como efecto de su conflicto interno. Revista de Relaciones Internacionales, Estrategia y Seguridad, 2(2), 94-126.

» Mosquera, J. (2007, noviembre 7). El tapón del Darién, más 50 años de polémica. La Prensa, p. 1. Recuperado de https://impresa.prensa.com/opinion/taponDarien-anos-polemica_o_2150035179.html (14/o8/2019).

» Nicolas, L. (2007). La Route Interaméricaine au prisme de l'intégration régionale: vers un décloisonnement progressif des frontières de l'Amérique centrale. Flux, 4(70), 20-32.

» OIM (2007). Estudio investigativo para descripción y análisis de la situación de la migración y trata de personas en la zona fronteiriza Colombia-Panama. Bogotá: Nuevas Ediciones.

"Pereira Carneiro, C. (2016). Fronteiras Irmãs: Transfronteirizações na Bacia do Prata. Porto Alegre: Ideograf.

» Runk, J. (2015). Creating Wild Darién: Centuries of Darién $\square$ s Imaginative Geography and its Lasting Effects. Journal of Latin American Geography, 14(3), 127-156.

»Sánchez Acosta, J. (2009). Tapón del Darién: El Dilema del Desarrollo. Monografia en Ciencias Económicas, Universidad Nacional de Colombia.

"Scheibe, E. (2013). Integração Física e Integração Regional: A Iniciativa para Integração da Infraestrutura Regional Sul-Americana (IIRSA) como instrumento multiescalar de integração. Tesis de máster en Geografía, Univerisdade Federal do Rio Grande do Sul.

»Silva, A. (2015). Megaprojetos, Conflitos e Processo Decisório: A análise de uma controverrsia intemporal chamada Belo Monte. Tesis doctoral en Sociología, Universidade de Coimbra.

»Steiman, R. (2011). Áreas protegidas em zonas de fronteira. Para Onde!?, 5, 101121.

"Suman, D. (2007). Globalization and the Pan-American Highway: Converns for the Panama-Colombia border region of Darién-Chocó and its peoples. University of Miami Inter-american Law Review, 38(3), 549-614.

» Teixeira, V., Anselmo, R. (2011). Integração e conflitos na América do Sul: a fronteira amazônica. Uberlândia: Horizonte Científico.

»Viveros, S. (2009). Tapón del Darién: El dilema del desarrollo. Monografía en Ciências Econômicas, Universidad Nacional de Colombia. 


\section{Camilo Pereira Carneiro / pereiracarneiro.camilo@gmail.com}

Professor Visitante do Mestrado em Fronteiras e Direitos Humanos da Universidade Federal da Grande Dourados (UFGD). Doutor em Geografia pela UFRGS. Mestre em Geografia pela UFRJ. Bacharel em Geografia pela PUC-Rio e Bacharel em Direito pela PUC-Rio. Áreas de interesse: Geografia Política, Fronteiras, Conflitos Internacionais e Cartografia Temática.

\section{César Augusto Reolon / cesar.reolon@hotmail.com}

Discente do curso de Relações Internacionais da Escola Superior de Propaganda e Marketing (ESPM). Pesquisador do Núcleo de Estudo e Pesquisa em Relações Internacionais (NEPRI). Tem experiência na área de Relações Internacionais e Fronteiras na América Latina, com ênfase em Geografia Política e Conflitos Internacionais.

\section{João Pedro Portela / jpedromorlinportela@gmail.com}

Discente do curso de Relações Internacionais da Escola Superior de Propaganda e Marketing (ESPM). Pesquisador do Núcleo de Estudo e Pesquisa em Relações Internacionais (NEPRI). Tem experiência na área de Relações Internacionais e Fronteiras na América Latina, com ênfase em Geografia Política e Conflitos Internacionais. 